\title{
Fixing the fatal flaw in emergency planning
}

Previously published at www.cmaj.ca

A re we prepared for a disaster? We certainly should be, given that we've invested hundreds of billions of dollars internationally to help communities respond to emergencies. But our system of preparedness has a fundamental flaw: emergency response plans are developed without incorporating the knowledge of the people who need to be protected.

Unquestionably, emergency planners have critically important expertise for designing protective strategies. But without listening to the public, they can't be aware of problems their plans may create. As a result, some people who could be protected by following emergency instructions may be unable to follow them. For others, the strategy designed to protect them may actually put them or their family members in danger.

The world saw the results of that kind of top-down planning in 2005, when Hurricane Katrina hit the southern United States. Many residents of New Orleans could not follow evacuation instructions because of barriers that had not been identified or addressed beforehand.

In 2004, the New York Academy of Medicine documented this problem in its review of preparations for terrorist-initiated dirtybomb explosions and smallpox outbreaks. The study report, entitled Redefining Readiness, ${ }^{1}$ predicted that millions of people may be put at risk if response strategies are not based on what people will actually face in an emergency. To identify those problems, the academy worked with four communities in the United States to develop a process of community engagement that enables the people who need to be protected to look at emergencies from their own point of view.

Take, for example, emergencies in which people would be told to stay where they are. ${ }^{2}$ Following this instruction sounds simple enough. But what if staying inside the building they happen to be in is more dangerous than going outside because toxic substances can come into the building? What if these people lack access to critical medications, facilities or supplies? Or they are in overcrowded conditions with unruly or violent people? What if protecting themselves by sheltering in place will endanger others who depend on them but are elsewhere, such as children or disabled family members?

The guidance that people and organizations are being given to prepare for emergencies does not address most of these issues. In fact, sometimes it makes matters worse. For example, people are told to keep a supply of food and water in their homes, and most keep their medications there as well. But in a shelter-in-place emergency, many people won't be at home. So the food, water or medicine they put aside won't be available to them. People are being told to identify places for family members to reunite. But what if they would have to go through a danger zone to get there? Although instructions describe how to identify and seal "safe rooms" in homes, schools and other buildings, they pay little attention to assuring that the rooms can accommodate the number of people likely to need shelter, provide them with breathable air or give them safe access to water, food, lavatories and medical supplies.

By incorporating and acting on the public's knowledge, it is possible to fix the flaw that is undermining efforts at preparedness.

Admittedly, involving a large and representative group of community residents in preparedness planning is not easy, even if it is for their protection. Many are busy. Their priorities are more immediate. They don't think anyone will take them seriously. They don't think they have anything to contribute. They'd rather someone else do the work. The timing of public consultations, the approaches used and the purpose of the discussions are often at issue.

But given that issues of survival are at stake, emergency planners must overcome these obstacles. The Redefining Readiness process offers comprehensive guidance for doing so.

Meetings at four demonstration sites were held in places where all of the participants felt safe and comfortable. All of their contributions were valued - and treated as valuable. Complete records were kept of what was said, and ideas were compiled and shared; no ideas were eliminated or reinterpreted. Together, participants identified both potential problems and ways to address them.

Out of this process, the groups created practical "issue sets" tailored for households, workplaces, schools and governments. ${ }^{3}$ They also created a manual for the engagement process to offer other communities a way to develop effective plans for the emergencies that are most likely to occur in their areas.

The challenge to our various levels of government now is to provide communities with incentives and supports to put such a process into practice - before people suffer and die unnecessarily in the next disaster.

\section{Roz D. Lasker MD}

Clinical Professor of Health Policy and Management,

Mailman School of Public Health,

Columbia University,

New York, NY

Noni Macdonald

Section Editor, Public Health

Paul C Hébert

Editor in Chief

CMAJ

Editorial advisory team: Ken Flegel MDCM MSc and Joan Ramsay BA

Competing interests: Roz Lasker was director of the Division of Public Health and the Center for the Advancement of Collaborative Strategies in Health at the New York Academy of Medicine from October 1995 to March 2009. Please see www.cmaj.ca/misc/edboard.shtml for the statements of Noni Macdonald and Paul Hébert.

Cite as CMAJ 2009. DOI:10.1503/cmaj.091820

\section{REFERENCES}

1. Lasker RD. Redefining readiness: terrorism planning through the eyes of the pub lic. New York (NY): the New York Academy of Medicine; 2004. Available: www .redefiningreadiness.net/rrstudy.html (accessed 2009 Oct. 14).

2. Lasker RD, Hunter ND, Francis SE. With the public's knowledge, we can make shelter ing in place possible. New York (NY): the New York Academy of Medicine; 2007. Available: www.redefiningreadiness.net/pdf/sipreport.pdf (accessed 2009 Oct. 14).

3. Lasker RD. Preparing to shelter in place: issues for households to consider; issues for work places to consider; issues for schools and early childhood/youth programs to consider; issues for governments to consider. New York (NY): the New York Academy of Medicine; 2007. Available: www.redefiningreadiness.net/rrsip .html (accessed 2009 Oct. 14).

All editorial matter in CMAJ represents the opinions of the authors and not necessarily those of the Canadian Medical Association. 